\title{
In Memoriam of My Friend Michio Nishida
}

It was a very sad time when our colleague and friend Michio Nishida passed away prematurely when he lost his battle with liver cancer. His enthusiasm for scientific progress and his commitment to novel therapeutic strategies for fighting lymphoma and autoimmune diseases were recognized and respected by all those who were associated with him. In Japan, Michio was instrumental in making significant contributions to the partnering and development of rituximab. He interacted with visionary leaders and coordinated efforts at preclinical and clinical sites to resolve issues as well as adhere to a strict time line for the development and regulatory approval of rituximab in Japan.

As Chief Scientific Officer at IDEC Pharmaceuticals, I worked closely with Michio in forming alliances and partnerships with several Japanese pharmaceutical companies to support the early research and preclinical development of antibodies for autoimmune disease therapy. These included antibodies for CD40L, CD80, and CD23, among others. During these interactions, Michio earned the respect of scientists and business associates alike, as he demonstrated a deep and a comprehensive knowledge of the science and, particularly, his great competence in pursuing challenging development strategies.

After retiring from IDEC, Michio continued his pursuit for the discovery and development of a second-generation anti-CD20 antibody for therapy of non-Hodgkin's B-cell lymphoma. Unfortunately, he did not live long enough to see this effort to come to fruition.

On a more personal level, Michio was a warm and hospitable friend. He loved life and his family, especially his wife Yoko and daughter Emi. He always enjoyed a glass of California wine with colleagues and friends. He is missed by all.

Dr. Nabil Hanna

Rancho Santa Fe, California 